\title{
Effectiveness of Context-Based Strategy for English Learning among Chinese Middle School Students
}

\begin{abstract}
Yibu Luo ${ }^{*}$, Xiangting Chen ${ }^{2}$
${ }^{1}$ Faculty of Arts, Programme of Applied Linguistics, the University of Melbourne, Grattan Street, Parkville, Victoria, VIC 3010, Australia

${ }^{2}$ Faculty of Education, Programme of TESOL (Teaching English to Speakers of Other Languages), the University of Melbourne, Grattan Street, Parkville, Victoria, VIC 3010, Australia

*Corresponding author: Yibu Luo, 18870817960@163.com

Abstract: Currently, a growing number of educators are aware of the need to look for new approaches to replace the "spoonfeeding" method. Therefore, the context-based strategy began to emerge. This study aims to investigate how students derive information through contextual clues by examining the progress of Chinese middle school EFL students in terms of word recognition. The participants of this study included 20 eighth grade students from the same middle school. The participants sat for two different quizzes: a contextual vocabulary quiz (quiz A) and a direct instruction quiz (quiz B). In quiz A, the participants inferred the meaning of the target words from the example sentences, whereas in quiz $B$, the students utilized the accompanying English explanation to guess other new words. These students were in the experimental and control conditions, respectively. The two quizzes comprised of 15 multiple choice questions (MCQ) which differentiated the participants' word recognition response to two different learning methods. There were two significant findings from this study. First, the results showed that the context-based strategy leads to a better vocabulary learning performance compared to the direct instruction strategy. Second, although it is not as effective as the context-based strategy, the direct instruction strategy may assist EFL learners in remembering words in short term.
\end{abstract}

Keywords: Context-based strategy; Context clues instruction; Word recognition; Direct instruction; Contextual analysis

Publication date: September 2021; Online publication: September 30, 2021

\section{Introduction}

\subsection{Background information}

Vocabulary instruction is an essential component of language learning. As a basic important but difficult point, vocabulary mastery is of great significance in the process of improving English literacy skills. Nagy stated that the correlation between vocabulary and reading comprehension ability is reciprocal and bidirectional because a person's reading speed and ability to seize information can be improved by enlarging vocabulary ${ }^{[1]}$. Prior research has shown that many L2 English learners found it challenging to guess the meaning of unfamiliar words from the original contextual information. Many students are able to read words, but they do not know, unable to use, or identify the contextual information in or around the recognized words to infer or derive the meaning of any unknown words they encounter while reading content area textbooks ${ }^{[2]}$. Traditionally, rote learning is characterized by cognitive load and is insufficient for inferring textual meaning. Furthermore, educators have found that the skills of talents are not equal to the ambition of developing applied bilingual talents when traditional spoon-feeding is used in education to train talents with competitive ability in the new century. Therefore, a growing number of Chinese students are objecting spoon-fed education and rote learning. In turn, this has made many researchers perceived that 
explicit vocabulary instruction, such as contextual analysis, may play a prominent role in learning words [3]. Mart stated that a context-based strategy does not only help learners to absorb grammatical structures but also clarify on how these structures apply to specific contexts ${ }^{[4]}$. Lai and Hu stressed that in the absence of a sufficient context, modern technology do not to exert effective assistance in second language learning [5].

Three main areas of concern are recognized in this study, which include enhancing English reading skills, coping with contextual vocabulary analysis tests, and expanding students' vocabulary to achieve high-level input comprehension.

\subsection{Research question}

(1) To what extent do context-based instruction assist Chinese EFL learners in acquiring L2 English vocabulary as compared to direct instruction?

(2) Which of these two instructions is more likely to have a significant positive impact on student's vocabulary learning?

\subsection{Significance of the study}

The study aims to contribute to language learning research in two ways. First, it aims to show how English vocabulary instruction can be improved and second, to assist learners to recognize the effectiveness of the context-based strategy for English vocabulary instruction. The research about these aspects of language learning is significant and meaningful in regard to the teaching of English as second language (ESL) in China. Findings from this research would contribute to the popularization of the context-based strategy in Chinese students' English vocabulary learning, thus encouraging more students to practice the skills of deriving target information from contexts.

Although several studies have confirmed that the context-based strategy is beneficial in English vocabulary learning as foreign language (EFL) learners, researchers rarely study the use of the strategy among learners from mainland China. In regard to that, this study aims to fill in the research gap. By testing the efficacy of the proposed method for contextual vocabulary instruction among lower intermediate EFL learners, this study offers a practical foundation for pedagogical decisions when implementing the contextbased strategy. This study attempts to prove the efficacy of context-based learning over direct instruction approach by comparing the posttest performance of the same participants after using the two methods.

\section{Literature review}

\subsection{Theoretical framework}

The context-based strategy for second language learning refers to utilizing scenarios to simulate students' social context ${ }^{[6]}$. This strategy uses practical experiences or fictitious examples in the classroom instead of theoretical teaching methods. According to Avargil and other researchers ${ }^{[7]}$, context-based pedagogy focuses on student-centered activities and inquiry-based laboratory investigation while minimizing traditional lectures and 'cook-book type' laboratories. In other words, this strategy allows learners to focus on understanding what has been presented to them rather than the language of the presentation, which can be regarded as content-based instruction (CBI). This approach can strengthen student's learning potential beyond their first language. The advantages of this strategy include intrinsically motivating students' interest as well as nurturing them to have greater adaptability and flexibility in word recognition. Students can then be exposed to daily language usage within relevant contexts instead of isolated fragments of the language. Contextual analysis refers to a strategy that readers use to predict a word from the context where 
it appears. Nonetheless, deriving information from secondary language sources may be difficult for lowerlevel learners. Implicit language texts can confuse learners and give them the impression that they do not fully comprehend new words. In contrast, direct instruction allows instructors to teach by explicit, guided instructions and theoretical knowledge explanations ${ }^{[8]}$. One of the strengths of direct instruction is efficiency. Students only need to follow the instructions step-by-step to attain the learning objectives. However, the structure of direct instruction may be inflexible and hinder the creativity of learners. Instructors need to have subject matter expertise and be well prepared ahead of time so that they can effectively explain a certain knowledge information to develop learners' thinking skills.

\subsection{Summary of primary research}

Previous literatures primarily focused on how the contextual-based strategy affects learners' vocabulary and reading. In a study conducted, learners who received context-based instruction demonstrated better reading comprehension than those who received instruction using the "wide reading" method ${ }^{[2]}$. Ilter's research is used to explain the impact of the context-based strategy on reading comprehension ${ }^{[3]}$ and vocabulary development [2]. A study conducted by Luo and Sun on EFL learners' word recognition processes when reading unfamiliar texts is interrogated ${ }^{[9]}$. Secondary research articles by Nagy ${ }^{[1]}$ and Mart ${ }^{[4]}$ demonstrated the significance of context-based strategy for vocabulary and grammar instruction. Holmes ${ }^{[10]}$ and Nelson ${ }^{[11]}$ also outlined context-based linguistic activities in detailed.

Recent primary research on context-based strategy for English learning investigated the impact of the strategy on intermediate learners' word recognition processes.

Luo and Sun ${ }^{[9]}$ interviewed two intermediate Chinese learners using a "think out loud" method. The study showed that these learners either skipped challenging words or attempted to guess them, which were regarded as obstacles in text comprehension. The results also revealed that Chinese learners commonly used root words to infer meaning. For example, learners merely need to understand the meaning of "ache" to guess the meaning of "stomachache" or "earache."

In Nelson's research ${ }^{[11]}$, learners were required to use newly acquired, challenging vocabulary in a classroom discussion. Subsequently, each learner's proficiency of these words was measured via a cloze quiz. The study aimed to identify the presence of a correlation between students' perceived language learning and the empirical findings related to contextual learning. In that study, the learners were reluctant to accept the context-based strategy because they felt that rather than engaging in contextual learning, simply memorizing vocabulary yielded faster short-term results. However, learners were found to be more likely to accept the strategy when applied over long-term (five years).

İlter has carried out investigations to measure the extent of the impact of context-based strategy on reading comprehension ${ }^{[3]}$ and vocabulary development ${ }^{[2]}$ among learners with varying English language levels. The participants in these studies were assigned to experimental and control groups. The students in the experimental group were trained to guess the meaning of new vocabulary from the text, while the students in the control group practiced reading comprehension using the "wide reading" strategy. The instructional procedures for the experimental group included four steps: first, the introduction of strategy to locate contextual clues; second, the "Slow Advance" step, in which the reading speed would be slowed down; third, the "Stop and Rewind" step, in which the preceding sentences would be read again; fourth, the "Play and Question" step, in which once the meaning of a new word is guessed, the word is substituted with the new word and reading is continued. The control group also had four steps: first, the participants are grouped as pairs; second, when a partner is reading a text passage, the other needs to correct the errors from the text by listening; third, after reading, both students would use dictionaries to check the meaning of the new words from the text individually; fourth, after summarizing all the new words, each pair would discuss with each other any of the words that have ambiguous meaning. All the participants were involved 
in the two training programs twice a week for half a month. The final test results indicated that students from the experimental group had better learning performance than those from the control group.

These studies used several contexts to investigate learners' vocabulary learning processes. This study would like to investigate whether the context-based strategy will have the same effect on Chinese middle school students who have been brought up in the exam-oriented education environment. Several creative learning methods in previous literatures would be applied into this study, such as the "Stop and Rewind" step and substituting guessed words for unknown words. These detailed educational measures may have significant pedagogical implications for reducing Chinese students' academic burden on vocabulary memory.

\section{Methodology}

\subsection{Research design}

Two quizzes and two posttests were used to assess the English word recognition of eighth-grade students from a middle school in Nanchang. The study focused on analyzing the effects of context-based instruction on ESL learners and its educational value in supporting word recognition. A quantitative approach was used to measure the difference of efficacy of direct instruction and context-based instruction on the learning performance and comprehension process.

The data collected were used to compare the posttest performance of the participants using quiz A and quiz B to measure the effectiveness of the two instruction methods. The participants' grades for both quizzes were compared to demonstrate the learning approach that the participants preferred.

Convenience sampling was used as the sampling strategy. After attaining a certain level of familiarity with the students, the English teacher's assistant, who frequently interacted with the students was involved in the study.

\subsection{Participants}

The participants were lower intermediate EFL eighth grade students from a Chinese middle school in Nanchang, an inland second-tier Chinese city with a strong exam-oriented education environment. All the participants, with age between 15 and 16 years old (12 boys and eight girls), had taken English courses for at least six years before they were recruited for the study. The participants were selected based on their final examination grades from the previous semester. The top 20 students, with average scores of 85.55 points $(\mathrm{SD} \approx 8.21)$, were recruited to participate in this study. The reason for selecting the top 20 students was that they had demonstrated good middle school English knowledge, indicating that they have the potential to develop higher-level learning and thinking skills.

Weak students have been hypothesized to be more likely to guess the answers in multiple choice questions (MCQs), which would impact the validity and reliability of the experimental data. Therefore, 30 students with the lowest examination scores from the previous semester's English examination were excluded from the study. The participants selected were assumed to have some basic learning strategies, such as deducing the meaning of words from details provided, linking prior knowledge to text, scanning, and skimming.

\subsection{Instruments}

\subsubsection{Pretest $A$ and posttest $A$}

In this quasi-experiment, quiz $\mathrm{A}$ and quiz $\mathrm{B}$ are equivalent to the experimental and control conditions. Pretest A was adapted from the AP Language and Composition Vocabulary Quiz by an educationist, 
Deanna L. Nelson ${ }^{[11]}$, that applied the context-based strategy to develop students' word recognition. The quiz was revised from a cloze quiz to a MCQ quiz as it was hypothesized that the original quiz would be difficult for middle school students to answer. In total, 15 MCQs were included in the pretest. Example sentences which contained target words were presented, and the participants were asked to identify the meaning of each target word from the options presented, which included near-synonyms or synonyms of the target word. Pretest A aimed to assist the participants' comprehension of words using the context-based strategy. After quiz A, the participants were found to be more receptive to the context-based approach. The posttest assessed the participants' retention of the meaning of the target words presented in the pretest.

\subsubsection{Pretest and posttest (quiz B)}

The test format and the questions in pretest B and the posttest review were identical to those in pretest A. However, there was a difference in the question types. Participants were presented with English definitions of certain target words and then were asked to self-define the target words by selecting from the options provided, which included near-synonyms. Therefore, the focus of pretest $\mathrm{B}$ was to encourage the participants to memorize the target words by direct instruction. The posttest review aimed to demonstrate the effectiveness of language learning by direct instruction.

\subsection{Procedure}

Before formally administering pretest A and B, two students from classes other than that of the participants were enrolled for a pilot test to select the target vocabulary for the study. Each piloted quiz contained 20 MCQs. The results of the pilot test showed that the students took almost half an hour to complete the quizzes. The feedback from the students indicated that the 20 unknown words included in the quizzes were challenging. Based on the students' suggestions, the five most difficult words and a few misleading distractors were removed from the quizzes.

The top 20 students in the previous semester's English final examination were selected to participate in the two quizzes. The two quizzes were closed-book assessments without any dictionaries allowed.

On June 19, the participants were given 20 minutes to complete pretest A. The answer sheets were returned after grading and they were instructed to mark the correct option for each MCQ. Subsequently, the participants were taught on how to combine context clues to identify the meaning of the target words.

Five days later (June 24), the participants were requested to take part in posttest A. For the posttest, the participants were required to look for the Chinese meaning of 15 words within 15 minutes. The participants were then given 20 minutes to complete pretest B. After grading the pretest, the answer sheets were returned to the participants, and the $15 \mathrm{MCQs}$ were translated from English to Chinese. Subsequently, the researcher explained on how to deduce the correct options. Four days later (June 28), posttest B was conducted.

\subsection{Data analysis}

The researcher converted the participants' grades into data and input the data into the Statistical Package for the Social Sciences (SPSS) software, coding each variable with "score." In addition to retrieving descriptive statistics, the analysis pointed out the samples' grade intervals' percentages and frequencies. By measuring the central tendency, the mean, standard deviation, and range of the quiz scores were summarized after considering several essential parameters.

Statistical analysis was performed using t-test under the two conditions (experimental and control conditions). To be more specific, two paired-sample t-tests were conducted to contrast the pretests and posttests. The independent t-test was for the two posttests. Finally, several statistical charts were constructed to respond to the three research questions. 


\subsection{Ethical consideration}

Before obtaining the student representative's consent, the students and the incumbent mentor teacher were briefed about the consent form and the whole research procedure. In addition to gratitude for their participation, the students were given constructive feedbacks in regard to their quiz results, indicating the common types of mistakes that students made in quizzes, which would help them gain some tips in MCQs. In order to safeguard individual privacy, pilot test A and B were anonymous. However, since the researcher needed to investigate each experimental subject's different performance, two quiz reviews and two quizzes required participants to write their names. In order to ensure that the confidentiality in this study, the researcher labeled the participants with designated numbers rather than using their real names.

The researcher informed the participants regarding the tasks and the research purpose as well as stipulated their rights to withdraw from the research at any time. Throughout the study, any students who wished to withdraw from the study were respected. Except for one student who dropped out of the study, the other 20 students completed the whole process.

\section{Results}

\subsection{Means and standard deviations}

This study used descriptive statistics for the pretest and posttest measures in the experimental condition. The pretest and posttest standard deviations and standard score means are listed in Table 1.

Table 1. Means and standard deviations for context-based instruction (experimental) and direct instruction (control) conditions

\begin{tabular}{cccccc}
\hline \multirow{2}{*}{ Conditions } & \multirow{N}{*}{} & \multicolumn{2}{c}{ Pretest score } & \multicolumn{2}{c}{ Posttest score } \\
\cline { 3 - 6 } & & $\mathrm{M}$ & $\mathrm{SD}$ & $\mathrm{M}$ & $\mathrm{SD}$ \\
\hline Experimental & 20 & 8.95 & 2.625 & 10.40 & 4.018 \\
Control & 20 & 7.85 & 2.815 & 10.30 & 4.054 \\
\hline
\end{tabular}

As shown in Table 1, the experimental condition scores increased in the posttest $(\mathrm{M}=10.40, \mathrm{SD}=$ 4.018) from the pretest $(\mathrm{M}=8.95, \mathrm{SD}=2.625)$. The control condition scores also increased in the posttest $(\mathrm{M}=10.30, \mathrm{SD}=4.054)$ from the pretest $(\mathrm{M}=7.85, \mathrm{SD}=2.815)$. The academic performances of both conditions were close to each other. However, for both the experimental and control conditions, the standard deviation of the posttest score was higher than that of the pretest score because only 12 participants achieved a much higher posttest score than in the pretest. There are two explanations for the decline in the academic performance of the other eight participants: first, the participants were not convinced that the context-based strategy is conducive for vocabulary learning and second, some were too lazy to recite the words using the teaching methods after the pretest. It was discovered that a few participants used the "lucky dip" or "throw the dice" during the posttest. This phenomenon would have had a negative effect on the research conclusion.

Another notable feature of Table 1 is the extent of academic progression in the control group. Although the experimental condition has a higher mean score than the control condition, the participants in the control condition made greater progress compared to those in the experimental condition. This is because most participants felt that the question types of pretest B were harder than pretest A. To be more specific, the participants were able to guess the meaning of the target words by associating them with the meaning of the entire sentence in pretest A, whereas pretest B required just the English definition of the words. There is no obvious distinction compared with the Chinese explanation. In their views, it is not even as useful as reciting words using Chinese explanations. 


\subsection{Paired-sample t-test}

As reported in Table 2, paired-sample t-tests were used to compare the participants' pretest scores with their posttest scores to assess the level of vocabulary retention. As expected, the results proved that the two conditions achieved significant increase in their vocabulary memory level $(p<0.05)$. The mean score for the experimental condition exceeded that of the control condition. Nevertheless, due to the limited sample size, Pearson correlation (Experimental $=0.336$, Control $=0.401)$ proved that the pretest results do not have a strong linear correlation with the posttest $(0.3<\mathrm{r}<0.5)$.

Table 2. Paired-sample t-test for pretest/posttest A and pretest/posttest B

\begin{tabular}{|c|c|c|c|c|c|c|c|c|c|c|}
\hline \multicolumn{11}{|c|}{ Paired-sample t-test } \\
\hline & & \multirow[b]{3}{*}{ Mean } & \multicolumn{4}{|c|}{$95 \%$ confidence interval } & \multirow[b]{3}{*}{$\mathrm{t}$} & \multirow[b]{3}{*}{ df } & \multirow{3}{*}{$\begin{array}{c}\text { Sig. } \\
\text { (2-tailed) }\end{array}$} & \multirow{3}{*}{$\begin{array}{c}\text { Pearson } \\
\text { correlation }\end{array}$} \\
\hline & & & Standard & Standard & \multicolumn{2}{|c|}{ of the difference } & & & & \\
\hline & & & deviation & error mean & Lower & Upper & & & & \\
\hline Experimental & $\begin{array}{c}\text { Pretest A- } \\
\text { Posttest A }\end{array}$ & -1.450 & 3.993 & .893 & -3.319 & .419 & -1.624 & 19 & .012 & .336 \\
\hline Control & $\begin{array}{l}\text { Pretest B - } \\
\text { Posttest B }\end{array}$ & -2.450 & 3.900 & .872 & -4.215 & .625 & -2.810 & 19 & .011 & .401 \\
\hline
\end{tabular}

\subsection{Independent sample t-test}

Shown in Table 3, an independent sample t-test was used to compare the scores from posttest A and B to explore the significance of the data. Theoretically, the analysis results conclude that the experimental condition tended to achieve better posttest results than the control condition. However, the p-values were greater than 0.05 , indicating a lack of statistical significance. These results indicate that the study could not exclude the likelihood of a mere coincidence or generalize the findings. This is principally because of the small sample size, resulting in unconvincing outcomes. In order to understand more about the mechanism of this peculiar phenomenon, further studies are needed. Additionally, the p-value being greater than 0.05 shows that the shape of the data distribution reasonably matches well with a normal distribution.

Table 3. Independent sample t-test for posttest A and posttest B

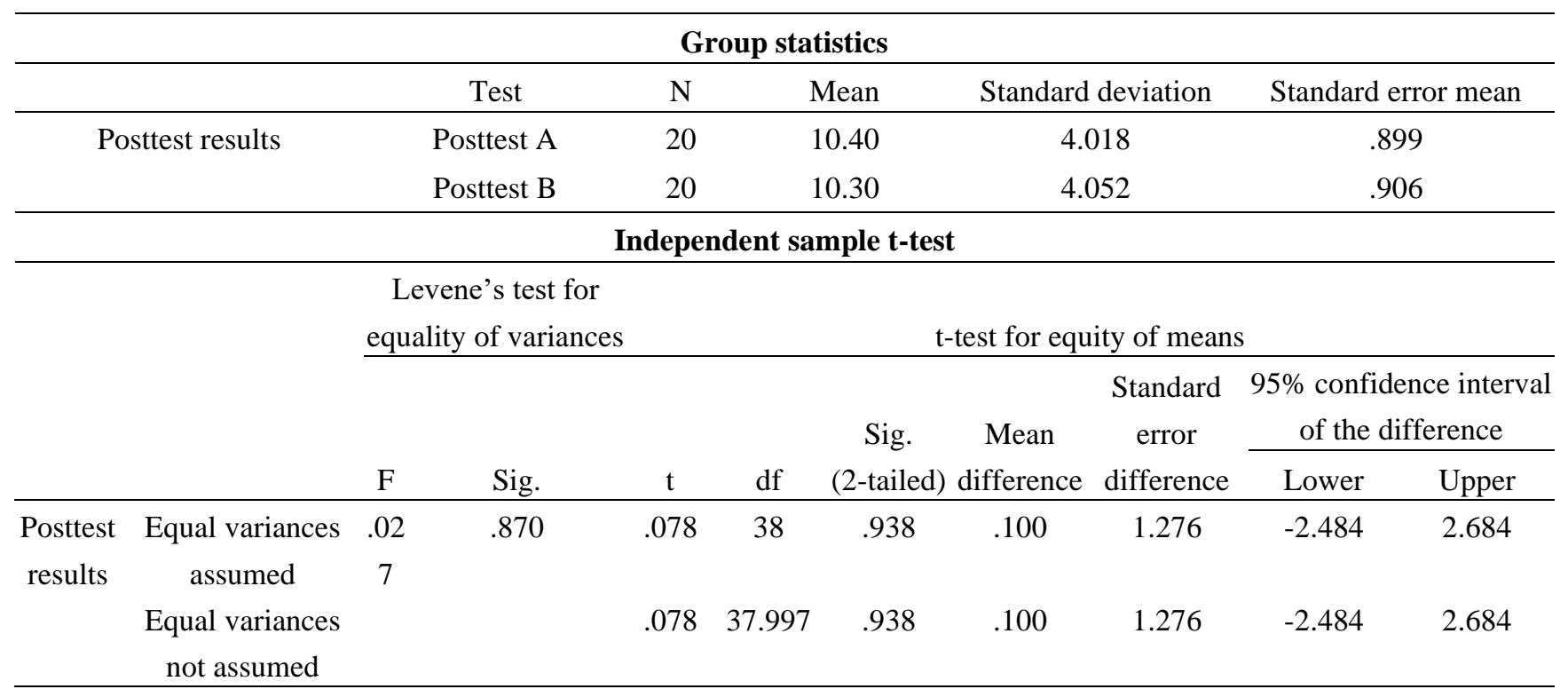




\section{Discussion}

\subsection{Summary}

The purpose of this study is to investigate the pedagogical influence of the context-based strategy for Chinese English learners. Although the limited statistical data is insufficient to represent the situation of English education in China, the findings are rather consistent with those of previous studies: the vocabulary of the participants in the experimental condition, who were instructed with the context-based vocabulary method, were more extensive than that of the control group ${ }^{[12]}$. In comparison between pretest $\mathrm{A}$ and $\mathrm{B}$, most participants indicated that they disliked memorizing vocabulary by English definition. They preferred to guess the meaning of new words from a specific context. The positive response from participants toward context-based instruction supports the implementation of this study's innovative approach to teaching English as a foreign language. In this study, the context-based strategy has more potential educational benefit than direct instruction. In addition, the academic results of the students in both the experimental and control conditions improved to a certain degree. This finding verifies that direct instruction is still effective for a considerable number of participants, and it is beneficial for the vocabulary development of EFL learners in short term. However, there are several flaws in the study that are yet to overcome.

\subsection{Limitation}

This study has high internal validity but limited in external validity. The main reason for the limitation is that the participants were all from one particular school. The results may be generalized to a population from a slightly different background, but not to all Chinese middle school students. Moreover, the emotions of the participants (e.g., anxiety) might have affected the validity of the study. The researcher had tried to help the students to relax but it was uncertain of whether it worked for the students.

This study has two risk factors that could undermine its internal validity. First, it is possible that the participants performed better on the quizzes in this study compared to their regular school activities because of the awareness that they were in an experiment. After learning that their teacher's assistant (the researcher) would conduct the study, the students who participated were extremely enthusiastic. Although the active cooperation from the students helped the researcher to complete the study efficiently, their growing enthusiasm might not be beneficial in reflecting their usual English proficiency level in this study. Second, the participants' ability to retain vocabulary would also depend on their learning initiative. The researcher was unable to closely supervise whether the students had determined the meanings of the words according to the context-based strategy. As a result, this study is limited in ascertaining the impact of context-based strategy on students' English learning. All of the above factors are beyond the researcher's ability to control. However, it is significant to take note that this is merely an elementary-level study. The purpose was to share the drawbacks and limitations in the steps that had been taken. On this foundation, educators would have the opportunity to take into account a similar venture and realize what needs to be improved. If this is the case, we sincerely hope for others to critique and improve on this study.

\subsection{Implication}

Despite the aforementioned flaws, the results from this study still confirm the pedagogical significance of context-based instruction. The implications of the study can be evaluated from three perspectives: learners, researchers, and instructors.

In regard to learners, this study does not only provide an easier learning approach rather than remembering the meaning of words, but also stresses that this approach can be widely used in advanced English reading. A large-scale language acquisition may not guarantee that non-English native speakers would acquire as much vocabulary as native speakers. In most cases, even advanced English learners need 
to guess the meaning of words by understanding the entire sentence.

In addition, language learners should have a strong motivation or incentive for learning a language. Being intrinsically and extrinsically motivated to learn a language may enable learners to approach their learning with an active as well as a positive approach, prompting conscious-learning strategies that encourage their learning beyond the classroom.

This study also provides a new perspective in the research on L2 vocabulary learning. In this way, researchers will be more aware of the significant influence of the strategy and conduct more multidirectional investigations. For example, when learners recite words, the brain response of learners toward different vocabulary learning methods can be manifested in the brainwaves whether different strategies have different influence on learners' neuronal activities.

For instructors, there can be further improvement in pedagogical methods in adapting to variations in students' learning styles. Interestingly, in Chinese middle schools, English teachers have begun to implement the context-based strategy in practicing cloze. Even in the Chinese high school entrance examination, one of the common reading questions is to determine the Chinese meaning of a new word from an article. Teachers have pointed out that this kind of question is a challenge for students, and it consumes a lot of time for them to get adjusted. The education authorities in China have realized the importance of the ability to gain information from contextual clues. The context-based method has begun to be widely used in English education in China.

In order to enhance learners' contextual analysis ability, instructors ought to expose learners to the environment of the target language as often as possible. Extensive exposure to the target language will help learners to acquire vocabulary, understand the patterns of sentence formation, and improve their pronunciation; all of this through a subconscious process, which maximizes learners' comprehensible input level.

\section{Disclosure statement}

The authors declare that there is no conflict of interest.

\section{Acknowledgements}

I wish to show my appreciation to my supervisor, Dr. Juyoung Lee; the English Language and Literature Studies (ELLS) Programme director, Dr. Edith Yan; the students' English teacher, Ms. Xiong; and the students who participated for their enthusiasm in this research.

\section{References}

[1] Nagy WE, 2005, Why Vocabulary Instruction Needs to Be Long-Term and Comprehensive, in Hiebert EH, Kamil ML, (eds), Teaching and Learning Vocabulary: Bringing Research to Practice, Lawrence Erlbaum Associates Publishers, 27-44.

[2] İlter İ, 2019, The Efficacy of Context Clue Strategy Instruction on Middle Grades Students' Vocabulary Development. RMLE Online, 42(1): 1-15.

[3] İlter İ, 2017, Teaching Word Meanings to Students at Different Reading Ability: A Controlled Assessment of the Contextual-Based Vocabulary Instruction on Reading Comprehension. Education and Science, 42(190): 437-463.

[4] Mart CT, 2013, Teaching Grammar in Context: Why and How? Theory and Practice in Language Studies, 3(1): 124-129. 
[5] Lai C, Yeung Y, Hu J, 2015, University Student and Teacher Perceptions of Teacher Roles in Promoting Autonomous Language Learning with Technology Outside the Classroom. Computer Assisted Language Learning, 29(4): 703-723. https://doi.org/10.1080/09588221.2015.1016441

[6] Trimmer W, Hawes P, 2015, Utilising Context in Learning, in Blessinger P, Carfora J, Inquiry-Based Learning for Science, Technology, Engineering, and Math (STEM) Programs: A Conceptual and Practical Resource for Educators, Emerald, United Kingdom, 241-256.

[7] Avargil S, Herscovitz O, Dori Y, 2012, Teaching Thinking Skills in Context-Based Learning: Teachers' Challenges and Assessment Knowledge. Journal of Science Education and Technology, 21(2): 207225.

[8] Englert CS, 1984, Effective Direct Instruction Practices in Special Education Settings. Remedial \& Special Education, 5(2): 38-47.

[9] Luo S, Sun X, 2018, A Case Study on Intermediate CSL Learners' Word Recognition Processes and Strategies in Contextual Reading Settings. Chinese Journal of Applied Linguistics, 41(3): 288-305.

[10] Holmes G, 1980, A Contextualized Vocabulary Learning Drill for French. Computers and the Humanities, 14(2): 105-111.

[11] Nelson D, 2008, A Context-Based Strategy for Teaching Vocabulary. English Journal, 97(4): 33-37.

[12] Özkan NK, Nurlu M, 2019, Implementation of Context-Based Vocabulary Teaching Method in Turkish Language Instruction for Foreigners. Journal of Language and Linguistic Studies, 15(3): 1139-1154.

[13] Gherwash G, Paiz J, 2019, Building Online Writing Labs: Recommendations for L2 Writing Content Development. TESOL Journal, 11(2). https://doi.org/10.1002/tesj.479

[14] Zhang H, 2015, Morphological Awareness in Vocabulary Acquisition among Chinese-Speaking Children: Testing Partial Mediation via Lexical Inference Ability. Reading Research Quarterly, 50(1): 129-142. 